\title{
Applicability of the theory of planned behavior in predicting intended use of Voluntary HIV Counseling and Testing services among teachers of Harari Region, Ethiopia
}

\author{
Shemsedin Omer $^{1}$, Jemal Haidar ${ }^{2}$
}

\begin{abstract}
Background: The predictive validity and applicability of Theory of Planned Behavior (TPB) may be a promising model for understanding and predicting intended behaviors to use VCT services. The need for theory based study would thus be essential in designing evidence based HIV-related interventions in the future.

Objectives: To examine the applicability of the Theory of Planned Behavior and the additional predictive role of perceived risk in predicting intended use of Voluntary HIV Counseling and Testing (VCT) services.

Methods: A cross sectional study design was conducted among 20 randomly selected schools in Harari Region between March and April 2009. Four hundred ninety seven randomly selected teachers consented to participate in the study giving a response rate of $87.8 \%$. Self administered questionnaire, adopted from the TPB was used for data collection. Multiple linear regression models were used to predict the role of important variables that can influence the intention to use VCT among teachers using SPSS version 15.

Result: More than half (53.7\%) who had never used VCT service were considered in the analysis for the intended VCT service use. All the modal variables correlated significantly with behavioral intention. Subjective norm ( $\mathrm{r}=0.45$, $\mathrm{p}<0.001)$, perceived behavioral control $(\mathrm{r}=0.42, \quad \mathrm{p}<0.001)$ attitude $(\mathrm{r}=0.33, \quad \mathrm{p}<0.001)$ and perceived susceptibility $(r=0.25, p<0.001)$, were significantly and positively correlated while perceived severity to the illness $(r=$ $0.14, \mathrm{P}<0.001$ ) was significantly but negatively correlated with behavioral intention. Perceived severity of the illness, normative belief and having high level of self control were the major predictors for intended use of VCT.

Conclusion: The study demonstrated that the TBP is a useful model for evidence based educational programs focusing mainly on creating supportive social system and strengthens their self efficacy for positive VCT uptake. [Ethiop. J. Health Dev. 2010;24(2):96-102]
\end{abstract}

\section{Introduction}

The most productive segments of the country including the basic education sectors are affected by HIV (1-3).

In the light of this epidemic, the government took several measures to curb the situation. One of the crucial measures taken by the federal ministry of health in 2000 was the provision of extensive Voluntary HIV counseling and testing (VCT) service for the larger community (4-6). The VCT service is provided by trained counselors either in government, public or private health facilities. By the end of the year 2007, there were 995 VCT sites integrated into public health facilities such as hospitals, health centers, and clinics which are either government or privately owned $(63.6 \%$ of the existing facilities). Although VCT sites have been used by apparently healthy members of the general public in region 13 to know their sero-status before marriage and other health related problem, the uptake among teachers is relatively low (7).

An extensive body of research has identified the social, psychological and cognitive factors related to utilization of VCT services (8-15). Some of the factors associated with the utilization of VCT included perceived susceptibility to HIV infection, partner involvement in counseling and testing, providers handling of confidentiality of HIV test results, perception of health status and a range of socio-demographic characters of clients.

In the effort to identify factors associated with the utilization of VCT services, some studies have applied theoretical models $(9,16)$, and few studies have tested the applicability of the theory of planned behavior (TPB) focusing on sexual behaviors such as intention to use a condom (17-19), intention to refuse sexual debut (18) and intended use of contraception (20) in Africa. Thus, the predictive validity and applicability of TPB in an African setting as shown by the aforementioned studies suggest that the TPB may be useful in designing HIV related interventions as well. It is worth considering the need for theory based studies to construct effective and evidence based educational programs that can assist in the control and prevention of the HIV infection (21-22).

The TPB (23) refers to a social cognition model that together with its precursor the Theory of Reasoned Action (TRA) (24-25) constitutes a promising model for understanding and predicting social behaviors in terms of

\footnotetext{
TPlanning and Programming Expert, Region Thirteen Health Bureau, Harar. e-mail: shamsedino@yahoo.com;

${ }^{1}$ Associate professor, School of Public Health, Addis Ababa University, P. O. Box 27285/1000,

e-mail:hjemal2009@gmail.com
} 
specifying the relationship between potentially modifiable behaviors or determinants. According to the TRA, people are rational actors who assume a causal chain that links behavior, belief and normative belief to behavioral intention and behavior, via attitude and subjective norms. This means intention to perform the behavior which is the function of attitude and subjective norms is the most immediate determinant of behavior performance (26). However, Ajzen and Madden proposed the TPB to account also for behaviors that were not under volitional control (27).

In the TPB, perceived behavioral control which is similar to Bandura's concept of self-efficacy (28) was added on a level with attitude and subjective norms as a predictor of intention so as to measure persons' perceived ability to perform a particular behavior in different situations (23). The TPB also specifies the determinants of attitudes, subjective norms and perceived behavioral control that are assumed to combine multiplicatively.

Although the core components of TPB model have been successful in predicting behavioral intention and subsequent behaviors, it has been recommended that the TPB is open to the inclusion of other variables if they increase the predictive utility of the model. This has been developed after the theory's core variables have been taken into account (23). Consistent with this reasoning about the sufficiency of this theory, the current study extended the TPB by adding a measure of perceived risk. This inclusion of perceived risk was deemed necessary because of the high prevalence of HIV in Ethiopia. High levels of the disease in any population might therefore influence risk perception as well as the uptake of VCT services. In addition, perceived HIV risk has been reported to have a significant role in decisions related to HIV prevention in previous studies that were not theory driven (10-12).

The objective of this study was therefore to examine the applicability of the TBP and the additional role of perceived risk in predicting intended use of VCT Services among randomly selected teachers in Region 13 and recommend its relative contributions for positive VCT uptake.

\section{Methods \\ Design: A cross sectional design was employed between March and April 2009 among teachers from Harari Region situated $525 \mathrm{KM}$ from Addis Ababa. The Region has 9 public and private VCT centers providing free services. At the time of the study there were 57 schools (31 urban and 26 rural) and 1,426 teachers in the region. Twenty schools (12 urban and 8 rural) were randomly selected using lottery methods for the study with a total of 603 teachers (429 urban and 174 rural) registered. Of the 603 registered and recruited teachers, with the exception of 37 off-duty teachers, all $(\mathrm{n}=566)$ were enrolled.}

Sample size: The sample was estimated by assuming an estimated prevalence of intention of VCT among teacher of $77 \%$ (29) with $4 \%$ margin of error, $95 \%$ confidence level, 1.5 design effect and additional $15 \%$ non response rate.

Instrument and variables: Self administered structured questionnaire, adapted from similar previous studies (30) and sample of questionnaires outlined by the author of Theory of Planned Behavior (TPB) that was modified to the study setting, was used to collect socio-demographic information and important variables (Figure 1). The questionnaire solicited respondents' socio-demographic information including school location, sex, age, and marital status. The important variables of interest collected in addition to socio-demographic characters, were HIV counseling (VCT) and intention to use the VCT services, attitude, normative belief, motivation to comply, control belief, power of control, perceived susceptibility and perceived severity to HIV. Each variable for the theoretical model was measured using a 5 Likert type of scales/questions ranging from 'very likely' $(=1)$ 'likely' (=2) 'neutral' (=3) 'unlikely' $(=4)$ to 'very unlikely' $(=5)$ as indicated below in each subtitle.

Intention to VCT: Respondents were asked to rate the extent to which they thought their use of VCT services the next time they were to go for health care services was likely to: avert their chances of HIV infection, make it possible for them to avoid transmitting HIV to their partners, result in a happy life if test results were negative. It also helps them plan confidently for their future, improve their partners' trust if test results were negative, and facilitate their seeking of anti-retroviral therapy if test results were positive.

Attitude: Items of behavioral beliefs were used together with those of outcome evaluation to compose the attitude scale. However, a three stage hierarchical regression analysis was run to test the expectancy-value assumption (whether a multiplicative attitude construct was better than an additive attitude construct (20).

Normative beliefs: Participants were asked to indicate the extent to which they thought their spouse/ partner, friends, fellow teachers, employer, neighbors, religious leaders, relatives, own children, pupils, and parents of their pupils were likely to appreciate their use of HIV counseling and testing services the next time they were to go for health care services.

Motivation to comply: Was measured by asking the respondents to rate the extent to which they thought it was important for them to comply with the wishes of their ten salient referents.

Subjective norms: We used normative belief items together with those of motivation to comply to compose the subjective norm scale. An empirical test on the expectancy-value assumption was done following similar procedures as outlined above for attitude. 
Control beliefs: Respondents were asked to indicate the extent to which they thought their partners were not in favor of their use of VCT services, cost related to VCT services were very high for them, they would die more quickly if they tested for HIV and were informed of a positive result; VCT service providers could not keep their HIV test results confidentially, it was not easy for them to disclose their HIV positive test results, they could be stigmatized if they were known or suspected to be HIV-infected, they could not afford to buy antiretroviral therapy if their HIV test results were positive.

Power of control: Respondents were asked to indicate how likely it would be for them to use VCT services the next time they were to go for health care services given the 8 control belief statements (presented under control beliefs).

Perceived behavioral control: We used control belief items together with those of power of control to compose the subjective norm scale.

Perceived risk: We measured perceived risk by asking respondents to rate the extent to which they agreed that they or their partners were probably already HIV infected.

Data collection process: Six teachers recruited from the eligible schools facilitated the data collection guided by a nurse supervisor. They were trained for two days on the objective of the study and techniques of assisting the study subjects whenever they come across difficulties in completing the questionnaire in order to avoid incompleteness of the questionnaire by the principal investigators. Each questionnaire was checked for completeness of the information by the facilitators the same day. To reduce the error arising from respondents, all questionnaires were rechecked for completeness and consistencies by the principal investigator. Data were edited initially manually and then entered into the computer and analyzed using the statistical package for the social sciences version 15. Multiple linear regression models were used to predict the role of important variables that can influence the intention to use VCT among teachers. Cronbach's alpha $(\alpha)$ was also applied to assess the various variables consistency in terms of their protective ability.

Ethical considerations: This study was cleared at the ethical review committee of the school of public health and the institutional review Board (IRB) of the medical faculty, Addis Ababa University for its ethical and scientific merit. Written consent of Region Thirteen Educational Bureaus was also obtained and a letter of support was written to all the respective heads of the selected school. An additional informed verbal consent was obtained from the respective teachers for their participation after the nature of the study was fully explained in their local languages. The right to withdraw from the study at any time was also communicated and respected.

\section{Results}

Four hundred ninety seven teachers participated in this study giving a response rate of $87 \%$. Among the 497 teachers; $266(53.5 \%)$ who had never used the VCT services were considered and analysed for the intended use of VCT services based on the Theory of Planned Behaviour (TPB). The median age of the participants was 32 ranged from 18 to 57 years with more teachers from urban settings $200(75.0 \%)$ than rural. There were more male $181(68.0 \%)$, married $152(57.0 \%)$ and diploma holders $141(53.0 \%)$ and earn $\leq 1500$ Birr 207 (77.8\%) (Table 1).

Table 2 depicts the mean and standard deviations for the components of the cognitive variables applied for 266 respondents who had never used VCT. The study group had better attitude, normative belief, motivation to comply, control belief, power of control, perceived severity to the illness and intentions to use VCT services. However, respondents felt less vulnerable to HIV infection as more than fifty percent of them perceived no susceptibility to HIV. The internal consistency reliability in terms of Cronbach's alpha ranged from 0.94 (power to control) to 0.67 (perceived severity to the illness). teachers in Harari Region, 2009.

\begin{tabular}{|c|c|c|}
\hline Variables & Numbers & Percents \\
\hline \multicolumn{3}{|l|}{ Age category } \\
\hline $15-24$ & 34 & 12.7 \\
\hline $25-34$ & 97 & 36.5 \\
\hline $35-44$ & 72 & 27.1 \\
\hline $45-54$ & 47 & 17.7 \\
\hline $55-64$ & 16 & 6.0 \\
\hline \multicolumn{3}{|l|}{ Median age $=32$ years } \\
\hline \multicolumn{3}{|l|}{ Teachers Location } \\
\hline Urban areas & 200 & 75.2 \\
\hline Rural areas & 66 & 24.8 \\
\hline \multicolumn{3}{|l|}{ Sex } \\
\hline Male & 181 & 68.0 \\
\hline Female & 85 & 32.0 \\
\hline \multicolumn{3}{|l|}{ Marital status } \\
\hline Single & 95 & 35.7 \\
\hline Married & 152 & 57.0 \\
\hline Divorced/ separated & 14 & 5.2 \\
\hline Widowed & 6 & 2.2 \\
\hline \multicolumn{3}{|l|}{ Education } \\
\hline $1-+1 / 12+1$ & 76 & 28.7 \\
\hline Diploma & 141 & 53.0 \\
\hline First degree & 49 & 18.3 \\
\hline \multicolumn{3}{|l|}{ Salary category } \\
\hline$\leq 1,500$ Birr & 207 & 77.8 \\
\hline$>1,500$ Birr & 59 & 22.2 \\
\hline
\end{tabular}


本

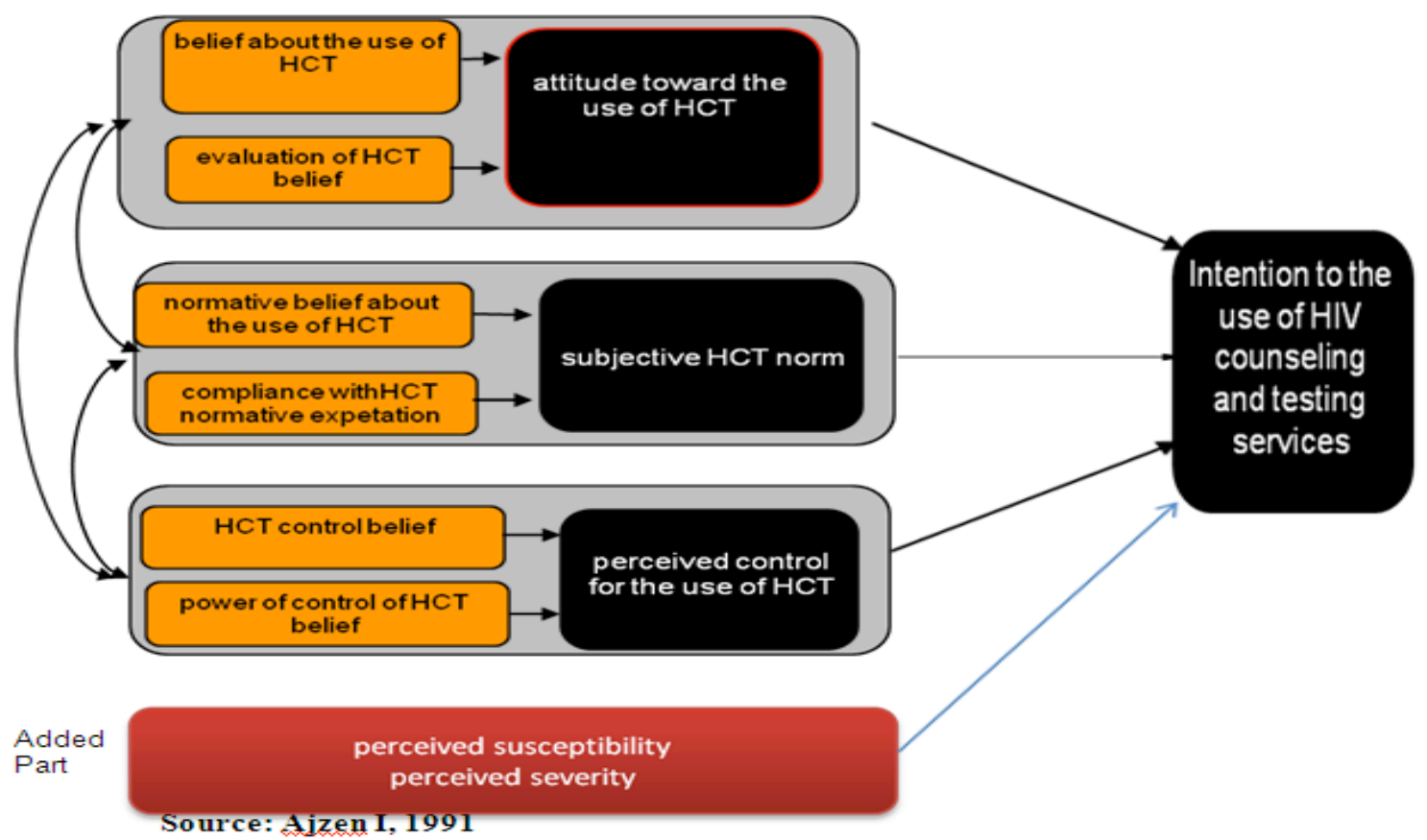

Figure 1: The extended theory of planned behaviour

Table 2: Descriptive statistics of the cognitive variables of teachers in Harari Region, 2009

\begin{tabular}{llllll}
\hline Components & $\mathbf{N}$ & Item & Mean & SD & $\alpha$ \\
\hline Attitude & 266 & 5 & 4.48 & 0.81 & 0.87 \\
Normative belief & 266 & 5 & 3.6 & 1.00 & 0.93 \\
Motivation to comply & 266 & 5 & 3.54 & 1.11 & 0.75 \\
Control belief & 266 & 5 & 3.35 & 1.09 & 0.88 \\
Power of control & 266 & 5 & 2.96 & 1.11 & 0.94 \\
Perceived susceptibility & 266 & 5 & 2.29 & 1.28 & 0.82 \\
Perceived severity & 266 & 5 & 3.46 & 1.25 & 0.67 \\
Intention & 266 & 5 & 3.38 & 1.25 & 0.92 \\
\hline
\end{tabular}

Table 3 displays the partial correlation coefficient among TPB variables, intention, attitude, subjective norm, perceived behavioural control, perceived severity, perceived susceptibility and monthly income. As shown, all the components of the TPB correlated significantly with behavioural intention. Subjective norm $(\mathrm{r}=0.45$, $\mathrm{p}<0.001)$ was significantly and strongly correlated followed by the perceived behavioural control $(\mathrm{r}=0.42$, $\mathrm{p}<0.001)$ and attitude $(\mathrm{r}=0.33, \mathrm{p}<0.001)$. Since they correlated positively an increase in the value of one TPB component was accompanied by an increased intention to use VCT. Perceived severity to HIV $(r=-0.14, \mathrm{P}<0.001)$ was also significantly and negatively correlated with behavioural intention. This indicates that as the perceived severity of the illness of individual increased intention to be tested decreased. Perceived susceptibility to the illness $(\mathrm{r}=0.25, \mathrm{p}<0.001)$ was positively correlated with intention to be tested. However total monthly salary did not correlate significantly with any of the TPB component. The internal consistency in terms of Cronbach's alpha was $0.92,0.71,0.89,0.93$ and 0.67 for intention, attitude, subjective norm, perceived behavioural control and perceived severity respectively.

Table 4 denotes the assessment of the applicability of the TPB model in predicting intended use of VCT services among the untested respondents using hierarchical regression analysis. Demographic variables (age, sex, educational status, marital status and location of school) were entered in the first step explaining 3.5\% of the variance in behavioural intention. Attitude and subjective norms were entered in the second steps and accounted for $25 \%$ of variance in intention. 
Table 3: Partial correlations (Pearson's r) among the components of planned behaviour, intention, attitude, subjective norm, perceived behavioural control, perceived severity, perceived susceptibility and monthly income of teachers in Harari Region, 2009

\begin{tabular}{|c|c|c|c|c|c|c|c|}
\hline Variables & 1 & 2 & 3 & 4 & 5 & 6 & 7 \\
\hline Intention & - & & & & & & \\
\hline Attitude & $0.33^{* *}$ & - & & & & & \\
\hline Subjective norm & $0.45^{\star *}$ & $0.30^{* *}$ & - & & & & \\
\hline Perceived behavioural control & $0.42^{* *}$ & 0.09 & $0.31^{*}$ & - & & & \\
\hline Perceived severity & $-1.14^{* *}$ & -0.10 & $-0.13^{*}$ & 0.05 & - & & \\
\hline Perceived susceptibility & $0.25^{\star *}$ & $0.14^{*}$ & 0.05 & -0.04 & $-0.43^{*}$ & - & \\
\hline Monthly income & $-0.15^{*}$ & -0.07 & -0.02 & 0.08 & 0.07 & -0.08 & \\
\hline
\end{tabular}

Significant $1{ }^{*} \mathrm{P} 0.05,{ }^{* *} \mathrm{P}<0.001$; controlled for age location and educational status

The perceived behavioral control was entered in the third steps and increased the variance by $6.5 \%$. The perceived susceptibility entered in the fourth steps and increased the variance by $6.1 \%$. Finally perceived severity was added to see its role, but no additional explained variance was observed. The statistically significant predictors that emerged in the final step were subjective norm $(\beta=0.31$, $\mathrm{p}<0.001)$, perceived behavioral control $(\beta=0.25$, $\mathrm{p}<0.001)$, perceived susceptibility $(\beta=0.22, \mathrm{p}<0.001)$, attitude $(\beta=0.19, \mathrm{p}<0.001)$ and age $(\beta=-0.13, \mathrm{p}<0.05)$. The strongest predictor for the intended use of VCT service was subjective norm followed by perceived behavioral continue, perceived susceptibility and attitude in descending order.

Table 4: Standard beta coefficients when intention to use HCT is regressed upon the TPB components and perceived susceptibility (PSU) $(n=266)$ of teachers in Harari Region, 2009

\begin{tabular}{|c|c|c|c|c|c|c|c|c|}
\hline \multirow[b]{2}{*}{ Components entered } & \multirow[b]{2}{*}{ Adj.r2 } & \multirow{2}{*}{$\mathbf{R 2}$} & \multirow{2}{*}{ F-change } & \multirow{2}{*}{ P-value } & \multicolumn{4}{|c|}{ Standardized regression coefficien } \\
\hline & & & & & $\beta P S U$ & $\beta P S U$ & $\beta P S U$ & $\beta P S U$ \\
\hline Demographic variables & 0.032 & 0.035 & 9.436 & $\mathrm{P}<.05$ & & & & \\
\hline$A+S N$ & 0.28 & 0.25 & 82.64 & $\mathrm{P}, .001$ & $0.21^{*}$ & $0.40^{*}$ & - & \\
\hline$A+S N=P B C$ & 0.33 & 0.065 & 22.89 & $P<.001$ & $0.21^{*}$ & $0.33^{*}$ & $0.24^{*}$ & \\
\hline$A+S N=P B C=P S U$ & 0.37 & 0.061 & 23.61 & $\mathrm{P}<.001$ & $0.19^{*}$ & $0.31^{*}$ & 0.25 & $0.22^{*}$ \\
\hline
\end{tabular}

Socio-demographic variable entered: Sex, age, educational status, location and total monthly income. $A=a$ attitude; $\mathrm{SN}=$ subjective norm; $\mathrm{PBC}=$ perceived behavioral control; $\mathrm{PSU}=\beta=$ standardized regression coefficient. ${ }^{*} \mathrm{P}<0.001$

\section{Discussion}

The present study demonstrates the applicability of the TPB model in predicting teachers' intention to use of the VCT services. The simultaneous predictive power of attitudes, subjective norms and perceived behavioral control on intention in terms of the adjusted $\mathrm{R}$ squared of 0.30 implies the model explained $30 \%$ variance in intention to use the service. This finding is in concordance with some previous studies conducted in Tanzania and Ethiopia $(23,31)$. According to the Tanzanian study, the TPB model explained $22 \%$ of variance in intention to use condom among school communities (18). Likewise in the intention to use contraception among adolescent girls in Ethiopia the model explained $29 \%$ of variance in behavioral intention (20).

As observed from the standardized regression coefficients, the results of this study indicated that intended use of VCT was primarily under subjective norm and attitudes while perceived behavioral control and perceived susceptibility had less weight. This implies that teachers use VCT services if they perceive less social pressure to do so. Previous studies conducted in African settings focusing on condom use $(17,18)$ and contraceptive use $(20)$ have shown that subjective norms were more important in predicting people's intention while attitudes is in conformity with the present study.
In one of the meta-analysis conducted across thirty different behaviors by Trafimow demonstrated that individuals to differ in the relative weights they place on attitudes and subjective norms. Likewise the predictors could also vary across different behaviors and a population group (31). This assertion was also observed in the present study. However, cautions need to be taken when subjective norm are considered for granted as evidence and that of normative expectations are less important when it comes to teachers' decision to use VCT services or not. Because the norms with respect to use VCT services have not yet been well established due to HIV/AIDS-related stigma and discrimination surrounding this behavior $(9,32)$. The fact that the relative weight of subjective norm being statistically significant before perceived behavioral control in the regression model indicates that other variables such as perceived susceptibility, normative belief and power of control could have played a role in utilization of VCT services.

In this study, VCT barriers such as fear of stigma and discrimination $(32,33)$, women's fear of adverse consequences if HIV test results are positive $(33,35)$, and suspicion about confidentiality of HIV test results (9, $36,37)$ are not under individual control but rather operate at the social-cultural level. Consistent observations were also reported in some previous studies of Tanzania $(38,39)$ and Ethiopia $(20,31)$.

Ethiop. J. Health Dev. 2010;24(2) 
Our findings support the notion that the inclusion of variables to the TPB might improve the external prediction of intention and behavior beyond the TPB variables (23). In this study, adding a measure of perceived risk contributed significantly to the explained variance in intended use of VCT services. Similar findings have also been reported in HIV/AIDS-related studies that were not theory driven (10-12). Moreover, the present finding corroborates earlier theory driven studies $(20,40,41)$ that have confirmed perceived risk to have a substantial independent effect over and above the components of the TPB model.

The present analyses revealed no significant effect of socio-economic status upon intended use of VCT services nor were socioeconomic status variables found to be effective modifiers of the relationships within the TPB model. This implies that the prediction of attitude, subjective norm and perceived behavioral control do not differ significantly among various categories of socioeconomic status of the studied group.

As for methodological concerns, the findings support the importance of testing the expectancy value assumption prior to the construction of scales for the TPB components $(20,42)$. Results of the hierarchical regression affirm the importance of including belief evaluations in the construction of attitude, subjective norms and perceived behavioral control scales. However, consistent with the findings of previous studies $(20,43)$ the multiplicative assumption as in the case of expectancy value model failed to account for additional variance in the TPB components and hence we adopted additive term.

In conclusion, the present study demonstrated that the TPB model is a useful tool for predicting and explaining intended use of VCT services. It has identified the important predictors to consider in promoting the use of VCT services. To alleviate psychosocial barriers related to use of VCT, it is necessary to encourage and supplement the favorable beliefs teachers have in terms of advantages and disadvantages associated with the use of VCT services.

Limitation of the present study: There was no prospective study that could establish the actual use of VCT services and this underlines the need for longitudinal studies in the future. From a measurement perspective, scaling beliefs and evaluations such as the narrow Likert's like scale may weaken the results. It is, thus important for future studies to consider using a wider range of scales to study intended use of VCT services.

\section{Acknowledgements}

Our great appreciation goes to the teachers who participated in the present study, without their participation, this study would ha not been possible. The support obtained from the respective Bureaus of health and education is dully acknowledged. We are also grateful to Dr. Mitike Molla for her support and constructive comments. This study was funded by the Ethiopian Public Health Association through the CDC project.

\section{References}

1. Bakilana A, Bundy D, Brown J. Accelerating the Education Sector Response to HIV/AIDS in Africa: A review of World Bank assistance, World Bank global HIV/AIDS program discussion paper. August 2005:1-5.

2. Bennell P, Hyde $\mathrm{K}$ and Swainson N. Impact of the HIV/AIDS epidemic on the education Sector in SubSaharan Africa: A synthesis of the findings and recommendations of three Country studies, center for international education. Feb. 2002: 75-97.

3. Asmelash A. Assessment of HIV/AIDS-Related Mortality among Primary and Secondary School Teachers in Addis Ababa (1998-2003) Using Verbal Autopsy. MPH thesis, December 2004, Addis Ababa, Ethiopia.

4. FMOH/HAPCO. Guidelines for HIV Counseling and Testing in Ethiopia. FMOH, Addis Ababa, Ethiopia, July 2007.

5. HAPCO/GAMET. HIV/AIDS in Ethiopia an epidemiological synthesis, the global HIV/AIDS program, Addis Ababa, Ethiopia, April 2008.

6. Federal Ministry of Health. Health and health related indicators. Planning and programming department, FMoH, Addis Ababa, Ethiopia, 2006/2007.

7. Omer S, Haidar J. VCT uptakes and associated factors among teachers from Harari Region, Ethiop J Health Dev. 2009;23(3):199-205.

8. Crosby RA, Miller KH, Staten RR, Noland M. Prevalence and correlates of HIV testing among college students: an exploratory study. Sexual Health, 2005;2:19-33.

9. De Paoli MM, Manongi R, Klepp KI. Factors influencing acceptability of voluntary counseling and HIV-testing among pregnant women in northern Tanzania. AIDS Care, 2004;16(4):411-425.

10. Fylkesnes K, Siziya SA. Randomized trial on acceptability of voluntary HIV counseling and testing. Tropical Medicine and International Health, 2004;9:566-572.

11. Gage AJ, Ali D. Factors associated with selfreported testing among men in Uganda. AIDS Care, 2005;17(2):153-165.

12. Holtzman D, Rubinson R, Bland S, Mcqueen D. HIV testing behavior and associated characteristics among U.S. adults, 1993 and 1994. AIDS and Behavior, 1998;2(4):269-281.

13. Mbago MC. Socio-demographic correlates of desire for HIV testing in Tanzania. Sexual Health, 2004;1:13-21.

14. Renzi C, Zantededeschi E, Signorelli C, Osborn J. Factors associated with HIV testing: Results from an Italian general population survey. Preventive

Ethiop. J. Health Dev. 2010;24(2) 
Medicine, 2001;32:40-48.

15. Wolf B, Nyanzi B, Katongole G, Ssesanga D, Ruberantwari A, Whitworth J. Evaluation of homebased voluntary counseling and testing intervention in rural Uganda. Health Policy and planning, 2005;20(2):109-116.

16. Meadows J, Catalan J, Gazzard B. 'I plan to have the HIV test': predictors of testing intention in women attending a London antenatal clinic. AIDS Care, 2001;5:141-148.

17. Bosompra K. Determinants of condom use intentions of university students in Ghana: an application of the Theory of Planned Behavior. Social Science and Medicine, 2001;52:1057-1069.

18. Lugoe WL, Rise J. Predicting Intended condom use among Tanzanian Students Using the Theory of Planned Behavior. Journal of Health Psychology, 1999;4(4):497-506.

19. Wilson D, Zenda A, McMaster J, Lavelle S. Factors Predicting Zimbabwean Students' Intention to use Condoms. Psychology and Health, 1992;7:99-114.

20. Fekadu Z, Kraft P. Predicting Intended Contraception in a sample of Ethiopian Female Adolescents: The Validity of the Theory of Planned Behavior. Journal of Psychology and Health, 2001;16:207-222.

21. Fishbein M, Ajzen I. Theory-based behavior change interventions: Comments on Hobbis and Sutton. Journal of Health Psychology, 2005;10: 27-31.

22. Kok G, Schaalma H, Ruiter R, Empelen P. Intervention Mapping: A Protocol for Applying Health Psychology Theory to Prevention Programs. Journal of Health Psychology, 2004;9(1):85-98.

23. Ajzen I. The Theory of Planned Behavior. Organizational Behavior and Human Decision Processes, 1991;50:179-211.

24. Ajzen I, Fishbein M. Understanding attitudes and predicting social behavior. 1980; Englewood Cliffs, NJ: Prentice-Hall.

25. Fishbein M, Ajzen I. Belief, Attitude, Intention and Behavior. 1975, New York: Wiley.

26. Ajzen I. From Intentions to actions: A theory of planned behavior, 1985. In J. Kuhl \& J.

27. Ajzen I, \& Madden T.J. Prediction of goal directed behavior: attitudes, intentions and perceived control. Journal of Experimental Social Psychology, 1986;22:453-474.

28. Bandura A. Self-efficacy Mechanism in Human Agency. American Psychologist, 1982;37:122-147.

29. Mohammed F. Factors related to voluntary counseling and testing among 15-49years urban community of Harar. MPH thesis, June 2000, Addis Ababa Ethiopia.

30. Conner M, Sparks P. The Theory of Planned Behavior and Health Behaviors. In M. Corner \& P. Norman (Eds.), Predicting Health Behavior, 1995;121-162. Buckingham: Open University Press.
31. Molla M, Astrom N, Berhane Y. Applicability of the theory of planned behavior to intend and self reported condom use in rural Ethiopian population. AIDs care. 2007;19(3):425-431.

32. Trafimow D. The importance of subjective norms for a minority of people: between subjects and within subjects' analyses. Personality and Social Psychology Bulletin, 1986;22:820-828.

33. Day JH, Miyamura K, Grant AD, Leeuw A, Munsamy J, Baggaley R, et al. Attitudes to HIV voluntary counseling and testing among mineworkers in South Africa: Will availability of antiretroviral therapy encourage testing? AIDS Care, 2003;15:665-672.

34. Sangiwa MG, Vander SA, Grinstead O, Group TV. Client's perspective of the role of voluntary counseling and testing in HIV/AIDS prevention and care in Dar es Salaam, Tanzania. AIDS and Behavior, 2000;4(1):35-48.

35. Maman S, Mbwambo J, Hogan NM, Kilonzo GP, Sweat M. Women's Barriers to HIV Testing and Disclosure: Challenges for HIV-1 Counseling and Testing. AIDS Care, 2001;13:595-603.

36. Biswalo PM, Lie GT. Hospital-Based Counseling of HIV-Infected People and AIDS patients. In Klepp K, Biswalo P, Talle A. (Eds.), Young People at Risk. Fighting AIDS in Northern Tanzania, 1995:222-239. Oslo: Norwegian University Press.

37. Lie GT, Biswalo PM. HIV positive patient's choice of a significant other to be informed about the HIV test results: findings from an HIV/ AIDS counseling program in the regional hospitals of Arusha and Kilimanjaro, Tanzania. AIDS Care, 1996;8:285-296.

38. Kida IA, Åstrøm A. Correlates of the Intention to avoid Intake of Sugared Snacks among Tanzanian Adolescents. Journal of Gender, Culture and Health, 1998;3:171-182.

39. Masalu JR, Åstrøm A. Predicting Intended and Self-Perceived Sugar Restriction among Tanzanian Students Using the Theory of Planned Behavior. Journal of Health Psychology, 2002;6(4):435-445.

40. Norman P, Conner M, Bell R. The theory of planned behavior and smoking cessation. Health psychology, 1999;18:89-94.

41. Sutton S, Mc-Vey D, Glans A. Comparative test on the theory of reasoned action and the theory of planned behavior in the prediction of condom use intentions in a national sample of English young people. Health Psychology, 1999;18:72-81.

42. Evans MG. The problem of analyzing multiplicative composites: Interactions revisited. American Psychologist, 1991;46(1):6-15.

43. Armitage CJ, Conner $M$, Loach J, Willets D. Different perception of control: applying an extended theory of planned behavior to legal and illegal drug use. Basic and Applied Social Psychology, 1999;38:35-54. 